February 2000 - NREL/CP-500-27898

\title{
HAWT Dynamic Stall Response Asymmetries Under Yawed Flow Conditions
}

S. Schreck, M. Robinson, M. Hand, and D. Simms

Presented at the 2000 ASME/AIAA Wind Energy Symposium

Reno, Nevada

January 10-13, 2000
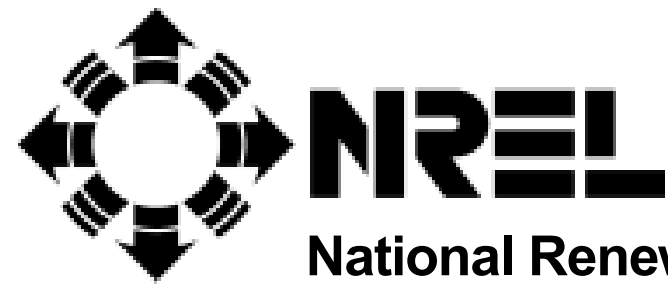

National Renewable Energy Laboratory

1617 Cole Boulevard

Golden, Colorado 80401-3393

NREL is a U.S. Department of Energy Laboratory

Operated by Midwest Research Institute $\bullet$ Battelle $\bullet$ Bechtel

Contract No. DE-AC36-99-G010337 


\section{NOTICE}

The submitted manuscript has been offered by an employee of the Midwest Research Institute (MRI), a contractor of the US Government under Contract No. DE-AC36-99G010337. Accordingly, the US Government and MRI retain a nonexclusive royalty-free license to publish or reproduce the published form of this contribution, or allow others to do so, for US Government purposes.

This report was prepared as an account of work sponsored by an agency of the United States government. Neither the United States government nor any agency thereof, nor any of their employees, makes any warranty, express or implied, or assumes any legal liability or responsibility for the accuracy, completeness, or usefulness of any information, apparatus, product, or process disclosed, or represents that its use would not infringe privately owned rights. Reference herein to any specific commercial product, process, or service by trade name, trademark, manufacturer, or otherwise does not necessarily constitute or imply its endorsement, recommendation, or favoring by the United States government or any agency thereof. The views and opinions of authors expressed herein do not necessarily state or reflect those of the United States government or any agency thereof.

Available electronically at http://www.doe.gov/bridge

Available for a processing fee to U.S. Department of Energy and its contractors, in paper, from:

U.S. Department of Energy

Office of Scientific and Technical Information

P.O. Box 62

Oak Ridge, TN 37831-0062

phone: 865.576 .8401

fax: 865.576.5728

email: reports@adonis.osti.gov

Available for sale to the public, in paper, from:

U.S. Department of Commerce

National Technical Information Service

5285 Port Royal Road

Springfield, VA 22161

phone: 800.553 .6847

fax: 703.605.6900

email: orders@ntis.fedworld.gov

online ordering: http://www.ntis.gov/ordering.htm

Printed on paper containing at least $50 \%$ wastepaper, including $20 \%$ postconsumer waste 


\title{
HAWT DYNAMIC STALL RESPONSE ASYMMETRIES UNDER YAWED FLOW CONDITIONS
}

\author{
S. Schreck, M. Robinson, M. Hand, and D. Simms \\ Applied Research Division \\ National Wind Technology Center \\ National Renewable Energy Laboratory \\ Golden, CO 80401
}

\begin{abstract}
$\underline{\text { ABSTRACT }}$
Horizontal axis wind turbines can experience significant time varying aerodynamic loads, potentially causing adverse effects on structures, mechanical components, and power production. As designers attempt lighter and more flexible wind energy machines, greater accuracy and robustness will become even more critical in future aerodynamics models. Aerodynamics modeling advances, in turn, will rely on more thorough comprehension of the threedimensional, unsteady, vortical flows that dominate wind turbine blade aerodynamics under high load conditions. To experimentally characterize these flows, turbine blade surface pressures were acquired at multiple span locations via the NREL Phase IV Unsteady Aerodynamics Experiment. Surface pressures and associated normal force histories were used to characterize dynamic stall vortex kinematics and normal force amplification. Dynamic stall vortices and normal force amplification were confirmed to occur in response to angle of attack excursions above the static stall threshold. Stall vortices occupied approximately one-half of the blade span and persisted for nearly one-fourth of the blade rotation cycle. Stall vortex convection varied along the blade, resulting in dramatic deformation of the vortex. Presence and deformation of the dynamic stall vortex produced corresponding amplification of normal forces. Analyses revealed consistent alterations to vortex kinematics in response to changes in reduced frequency, span location, and yaw error. Finally, vortex structures and kinematics not previously documented for wind turbine blades were isolated.
\end{abstract}

\section{NOMENCLATURE}

AOA angle of attack (deg)

$\mathrm{C}_{\mathrm{n}} \quad$ normal force coefficient

c chord length (m)

$\mathrm{c}_{\mathrm{p}} \quad$ pressure coefficient $\left(\left(\mathrm{p}-\mathrm{p}_{\infty}\right) / \mathrm{q}\right)$

DSV dynamic stall vortex

This material is declared a work of the U.S. Government, and is not subject to copyright protection in the United States.

$\begin{array}{ll}\mathrm{ft} & \text { feet } \\ \mathrm{Hz} & \text { Hertz } \\ \mathrm{K} & \text { reduced frequency }\left(\mathrm{c} \omega / 2 \mathrm{U}_{\mathrm{LOC}}\right) \\ \mathrm{m} & \text { meter } \\ \mathrm{mm} & \text { millimeter } \\ \mathrm{N} & \text { Newton } \\ \mathrm{q} & \text { dynamic pressure }\left(\mathrm{N} / \mathrm{m}^{2}\right) \\ \mathrm{p} & \text { static pressure }\left(\mathrm{N} / \mathrm{m}^{2}\right) \\ \mathrm{p}_{\infty} & \text { freestream static pressure }\left(\mathrm{N} / \mathrm{m}^{2}\right) \\ \mathrm{r} & \text { span location }(\mathrm{m}) \\ \mathrm{R} & \text { span length }(\mathrm{m}) \\ \mathrm{s} & \text { second } \\ \mathrm{t} & \text { time }(\mathrm{s}) \\ \mathrm{U}_{\mathrm{LOC}} & \text { cycle averaged local velocity }(\mathrm{m} / \mathrm{s}) \\ \mathrm{U}_{\infty} & \text { freestream velocity }(\mathrm{m} / \mathrm{s}) \\ \mathrm{V}_{\mathrm{DSV}} & \text { DSV convection velocity }(\mathrm{m} / \mathrm{s}) \\ \mathrm{x} & \text { chord location }(\mathrm{m}) \\ \alpha & \text { angle of attack }(\mathrm{deg}) \\ \alpha_{\mathrm{m}} & \text { mean angle of attack }(\mathrm{deg}) \\ \alpha_{\omega} & \text { oscillation amplitude }(\mathrm{deg}) \\ \alpha+ & \text { nondimensional pitch rate }(\mathrm{c}(\mathrm{d} \alpha / \mathrm{dt}) / \mathrm{U}) \\ \gamma & \text { yaw error }(\text { deg }) \\ \psi & \text { instrumented blade azimuth angle }(\mathrm{deg}) \\ \omega & \text { blade rotation rate }(\mathrm{rad} / \mathrm{s}) \\ & \end{array}$

\section{INTRODUCTION}

Horizontal axis wind turbines (HAWT's) routinely experience significant time varying aerodynamic loads. Extreme aerodynamic loads impose correspondingly high structural loads on turbine blades and transmissions, thus appreciably shortening machine service life. In addition, extreme aerodynamic loads elicit power fluctuations that adversely impact power quality. These and other factors arising from unsteady aerodynamic loading conspire to drive up the overall cost of energy. Such problems are not unique to stall controlled HAWT's, since pitch controlled turbines frequently experience extreme aerodynamic loads in response to wind variations, inflow anomalies, and machine dynamics.

Though accompanied by multiple adverse effects, unsteady aerodynamic loads have stubbornly resisted mitigation via existing design strategies or devices. The lack of reliable methods for dealing with unsteady 
aerodynamic loads is due largely to the constraints on accuracy and reliability that currently limit prediction methods for HAWT aerodynamics. This situation, in turn, derives strongly from the lack of fundamental comprehension of the unsteady flow fields generated by HAWT's.

Current modeling approaches have been deemed adequate for predicting HAWT force and moment levels, subject to qualitative guidelines regarding regimes of validity. However, uncertainty remains as to whether these models accurately portray the physics of three-dimensional, unsteady, vortical flow fields that routinely occur in HAWT aerodynamics. To establish a more substantial basis for making these judgments, the current effort seeks to quantify vortex kinematics for three-dimensional, unsteady, vortex dominated flow fields observed on HAWT blades operating in yawed flow.

Multiple influences conspire to render dynamically stalled flows physically complex and challenging to comprehend. Viewed simplistically as a twodimensional process, these flows initiate when lifting surface angle of attack dynamically exceeds the static stall threshold. Soon thereafter, unsteady boundary layer separation gives rise to a small but energetic dynamic stall vortex. This vortex quickly grows, convects rapidly downstream, and soon sheds from the lifting surface. During this process, the vortex generates a region of low pressure on the lifting surface, causing dramatic lift amplification beyond static levels, followed by abrupt deep stall at vortex shedding. $[1,2]$ Surface pressure signatures confirm that this sequence of events occurs on HAWT blades [3-7], and constitutes a significant contribution to HAWT loads and yaw dynamics. [8]

The complexity of this situation is further compounded by the influence of three-dimensionality. All experimental work of this nature appears to have been carried out in wind tunnels, ensuring steady, uniform inflow. Still, complex spatial and temporal variations were observed in the resulting vortex dynamics. Freymuth [9] visualized the unsteady, threedimensional vortex structures elicited by various threedimensional lifting surfaces driven through diverse motion histories. Using surface pressure measurements, Robinson, et al. [10] documented the lift enhancement and prolongation due to vortex pinning and straining near the tip of a rapidly pitching wing. Also using surface pressure measurements, Lorber, Carta, and Covino [11] characterized dynamic stall at elevated Reynolds numbers over a broad parameter range, using a wing oscillating in pitch. These experiments showed significant three-dimensionality in stall vortex development and propagation, as well as modifications to these processes in response to unsteady parameter alterations.

Schreck, Addington, and Luttges [12] employed surface pressure data to characterize the vortex dynamics in the root region of a rapidly pitching wing. They noted vortex straining and pinning analogous to that at the tip, as well as similarly enhanced and prolonged lift generation. Unified comprehension of the vortex dynamics governing the root, midspan, and tip regions was provided by Schreck and Helin [13], by combining flow visualization with surface pressure topologies. In addition to vortex pinning near the wing tip and root, these experiments revealed radical vortex deformation near the wing midspan associated with dramatic spatial and temporal lift fluctuations. Subsequently, Piziali [14] confirmed the existence of these structures and interactions for higher aspect ratio geometries.

Superimposing rotation on a lifting surface, as occurs with HAWT blades, adds still other physical mechanisms and greater complexity. The widely cited experiments of Himmelskamp [15] indicate that stall delay and lift enhancement due to rotation were first noted for aircraft propellers. To explain these results, radial thinning and chordwise acceleration of the steady boundary layer, due to centrifugal forces and Coriolis effect, respectively, were postulated. A complementary theoretical analysis was performed by Banks and Gadd [16] for steady laminar boundary layers on a rotating blade at small incidence. They concluded that the zero shear stress separation criterion was avoided due to stabilization arising from a linear adverse external velocity gradient.

Later experimental and analytical research was carried out in the rotorcraft field. McCroskey and Yaggy [17] carried out a theoretical analysis for quasi-steady rotor blade flows with small crossflows. For zero or favorable chordwise pressure gradient, the effects of crossflow due to rotor rotation were judged beneficial, especially in regions of incipient separation, but of smaller magnitude than crossflows due to rotor translation. It was also speculated that, in strong adverse pressure gradients, the rotationally induced crossflows played a more influential role. Subsequent rotor experiments [18] showed that centrifugal forces move the fluid significantly outward in separated regions, but are relatively unimportant regarding aerodynamic force augmentation.

More recent HAWT experiments, all employing surface pressure measurements, reached diverse conclusions regarding the impact of blade crossflows. Using field test data, Madsen and Christensen [19] concluded 
rotational effects to be of minor importance compared to the influences of aspect ratio and spanwise pressure gradient. Two other experiments were carried out in wind tunnels and arrived at different conclusions. Using two-dimensional airfoil performance as a baseline, Barnsley and Wellicome [20] stated that the combination of rotational and three-dimensional effects appeared to suppress the loss of leading edge suction across the entire span, compared to two-dimensional behavior. Alternatively, Ronsten [21] used rotating blade data as a baseline, and noted that rotation generated significant differences in lift behavior only at the pressure measurement station farthest inboard on the blade.

The current experimental investigation employs fullscale field test data in an attempt to isolate and characterize the fluid dynamic mechanisms responsible for pronounced aerodynamic loads under yawed rotor conditions. Unsteady blade surface pressure data acquired via the NREL Unsteady Aerodynamics Experiment have been exploited to quantify blade normal force generation as well as dynamic stall vortex kinematics. Analysis methodologies have been applied to these data to better understand the fluid dynamic mechanisms responsible for unsteady, separated, vortex dominated, three-dimensional, rotational blade aerodynamics generated by HAWT's.

\section{EXPERIMENTAL PROCEDURE}

The Unsteady Aerodynamics Experiment HAWT is well documented [22-24]. The downwind turbine employs a three-bladed rotor that is $10.1 \mathrm{~m}$ in diameter and coned $3.4^{\circ}$ downwind. The rotor turns clockwise (viewed from downwind) at a constant $71.6 \mathrm{rpm}$, is stall regulated, and has a maximum rated power of $19.8 \mathrm{~kW}$. A cylindrical tower $0.4 \mathrm{~m}$ in diameter supports the turbine at a hub height of $17.03 \mathrm{~m}$, with a rotor overhang of $1.32 \mathrm{~m}$. This generic configuration has been employed for Phases I through V of the Unsteady Aerodynamics Experiment.

Data from Phase IV were used for the investigation documented herein. The Phase IV rotor employed three rectangular planform blades of $5.03 \mathrm{~m}$ radius. Between 0.14 span and the tip, blade chord was constant $(0.457$ $\mathrm{m}$ ), and cross-section was uniform (NREL S809). Blade twist distribution, shown graphically in Figure 1, was optimized to yield $\alpha=15^{\circ}$ along the entire blade at a pitch angle of $3^{\circ}$ and a wind speed of $8 \mathrm{~m} / \mathrm{s}$.

For Phase IV, one of the three blades was instrumented as shown in Figure 2 to acquire detailed surface pressure data. Data used in the current work were obtained from the full pressure tap distributions located at $0.30,0.47,0.63,0.80$, and 0.95 span (Figure 2, lower). A full pressure tap distribution consisted of 22 taps distributed as shown in the upper portion of Figure 2. Taps were more densely distributed near the blade leading edge to better resolve the small structures and fleeting events typically observed in this region during dynamic stall events.

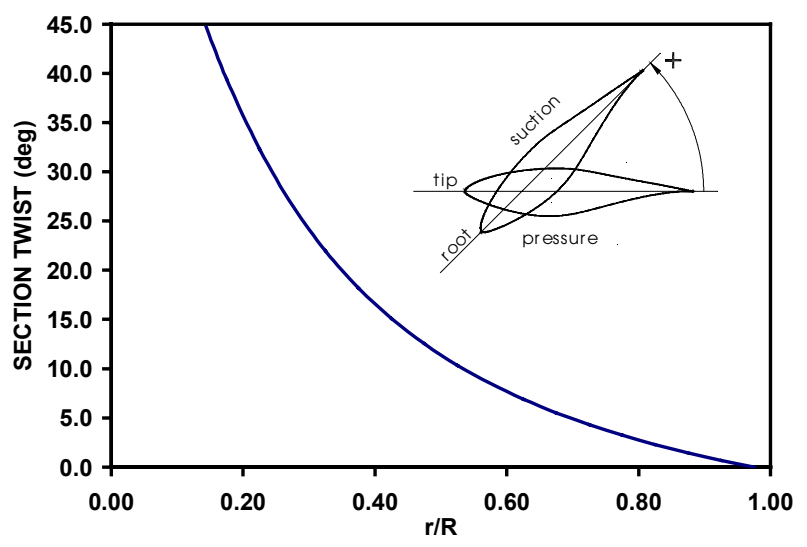

Figure 1. Twist distribution for Phase IV blades.
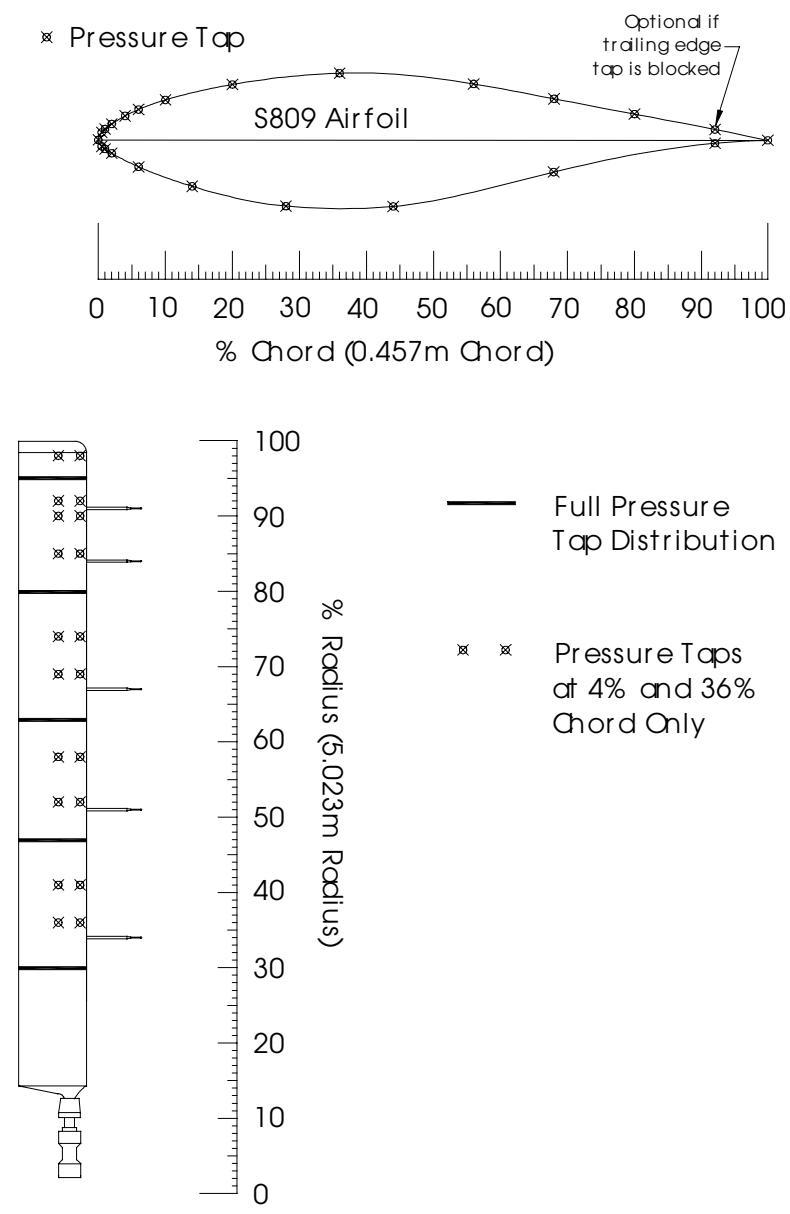

Figure 2. Pressure tap locations on Phase IV blades. 
Pressure taps were flush mounted at the blade surface, and had inside diameters of $0.69 \mathrm{~mm}$. From the taps, stainless steel hypodermic tubes having inside diameters of $0.69 \mathrm{~mm}$ transmitted the surface pressures to the pressure transducers. Hypodermic tubing lengths were kept less than $0.45 \mathrm{~m}$ to mitigate pressure delay and dispersion effects. Pressures were measured by five Pressure Systems Incorporated ESP-32 electronically scanned pressure transducers located inside the blade near the five full pressure tap distributions. Each of the transducer pressure inputs was scanned at $520.8 \mathrm{~Hz}$. In conjunction with the tubing frequency response, this provided antialiased digitization and minimal gain variation out to $55 \mathrm{~Hz}$. [22]

During Phase IV, dynamic pressures and inflow angles were measured near these five pressure tap distributions using five hole probes. Probes were mounted on cylindrical stalks at $0.34,0.51,0.67,0.84$, and 0.91 span, with the probe tip $0.37 \mathrm{~m}$ upstream of the blade leading edge. Probes were angled $20^{\circ}$ downward relative to the local chordline, allowing measurement of local flow angles between $-15^{\circ}$ and $55^{\circ}$. Five hole probe pressures were measured using the ESP-32 transducers described above. Local inflow angles measured by the five hole probes were converted to section angles of attack using an experimentally derived upwash correction. [22] Wind speed was measured 15 $\mathrm{m}$ upwind of the turbine using cup and sonic anemometers, and wind direction was measured at the same location using bi-vane indicators.

It is important to note that the blade geometries used for the Unsteady Aerodynamics Experiment are atypical. Multiple Unsteady Aerodynamics Experiment program phases were designed to provide a common data set for comparing three-dimensional blade geometry effects on aerodynamic performance. Hence, the blade geometry has been altered parametrically, and all other variables have been held as constant as physical design constraints would allow. The blade that will be tested next in the Unsteady Aerodynamics Experiment program will be a tapered and twisted blade resembling those currently used by industry. This blade will be tested in both a field (National Wind Technology Center) and wind tunnel (NASA Ames $80 \mathrm{ft}$ x $120 \mathrm{ft}$ ) environment, providing a comprehensive data set for developing and validating new aerodynamics codes.

\section{RESULTS AND DISCUSSION}

The entirety of Phase IV data comprises 75 campaigns, each of 10 minutes duration. For each campaign, the processed data file consists of 262 channels digitized at $520.8 \mathrm{~Hz}$. Overwhelming data volume combined with labor intensive data analysis procedures prevented consideration of the majority of Phase IV data. To render data analysis tractable, one Phase IV data campaign was selected for detailed examination on the basis of coarse level statistics. Coarse level statistics for all 75 Phase IV campaigns are summarized in Table 1. Campaign d403022 was judged to be typical of Phase IV data in terms of mean hub height wind speed $(10.1 \mathrm{~m} / \mathrm{s})$, mean wind direction $\left(303^{\circ}\right.$ true), and mean yaw error $\left(-11.5^{\circ}\right)$. The results documented herein were derived entirely from campaign d403022. During $\mathrm{d} 403022$, average blade pitch angle was $+2.3^{\circ}$.

\begin{tabular}{|l|r|r|}
\hline & \multicolumn{1}{|c|}{ Mean } & \multicolumn{1}{|c|}{ SD } \\
\hline Wind Speed $(\mathrm{m} / \mathrm{s})$ & 11.4 & 3.9 \\
\hline Wind Direction $(\mathrm{deg})$ & 286.9 & 15.8 \\
\hline Yaw Error $(\mathrm{deg})$ & -8.9 & 13.6 \\
\hline
\end{tabular}

Table 1. Aggregate statistics for all Phase IV campaigns.

\section{$\underline{\text { Stall } \alpha \text { and Stall } C_{n}}$}

Normal force amplification beyond static stall levels is known to be a reliable indicator of dynamic stall occurrence under two-dimensional conditions. [1,2] Two-dimensional wind tunnel test data show that static stall $C_{n}$ for the NREL S809 airfoil lies between 0.93 and 1.05 , depending on the test facility. Accordingly, to isolate those cycles in $\mathrm{d} 403022$ during which a stall vortex developed, stall $C_{n}$ (maximum $C_{n}$ during the cycle) at 0.30 span was examined for each of the 720 cycles in $\mathrm{d} 403022$. Those cycles wherein stall $\mathrm{C}_{\mathrm{n}}$ reached or exceeded 1.3 at the 0.30 span station were identified as containing a dynamic stall event. This criterion was subsequently validated by examining surface pressure histories for cycles thus identified.

The histogram in Figure 3 shows the frequency of stall $\mathrm{C}_{\mathrm{n}}$ magnitudes at 0.30 span for $\mathrm{d} 403022$. Of the 720 original cycles, 284 met the criterion for dynamic stall occurrence, attesting to the prevalence of dynamic stall occurrence during HAWT operation. Cycles were then selected from this subset of 284 according to cycle average yaw error, to uniformly characterize the yaw error range between $-45^{\circ}$ and $+45^{\circ}$. This selection procedure identified 21 cycles that were subsequently analyzed and the results presented herein.

Clearly, the cycle selection threshold of 1.30 identified stall $\mathrm{C}_{\mathrm{n}}$ 's at 0.30 span that substantially exceeded static levels. However, this ensured that selected cycles contained similarly amplified $\mathrm{C}_{\mathrm{n}}$ 's at span locations farther outboard, as well. Figure 4 plots stall $C_{n}$ versus 
stall $\alpha$ for all five blade span locations, for all 21 cycles. To highlight the normal force amplification due to dynamic effects, the static $C_{n}-\alpha$ curve for the NREL S809 airfoil, tested in the Colorado State University (CSU) wind tunnel, is included. The 0.30 span location showed the greatest degree of stall delay beyond static stall and associated $\mathrm{C}_{\mathrm{n}}$ amplification, with the highest 0.30 span stall $\mathrm{C}_{\mathrm{n}}$ reaching 2.81 at $\alpha=25.4^{\circ}$. Similar to 0.30 span, $C_{n}$ amplification was significant at 0.47 and 0.63 span, with several $C_{n}$ values between 1.5 and 2.0, and accompanied by stall postponement to $\alpha$ beyond static stall. At $0.80, \mathrm{C}_{\mathrm{n}}$ amplification remains evident, though small, as is stall delay. At 0.95 span, neither $C_{n}$ amplification nor stall delay is consistently observed for all 21 cycles. Similar trends in $\mathrm{C}_{\mathrm{n}}$ amplification and stall delay have been shown by Acker [25] for Phase IV zero yaw error conditions.

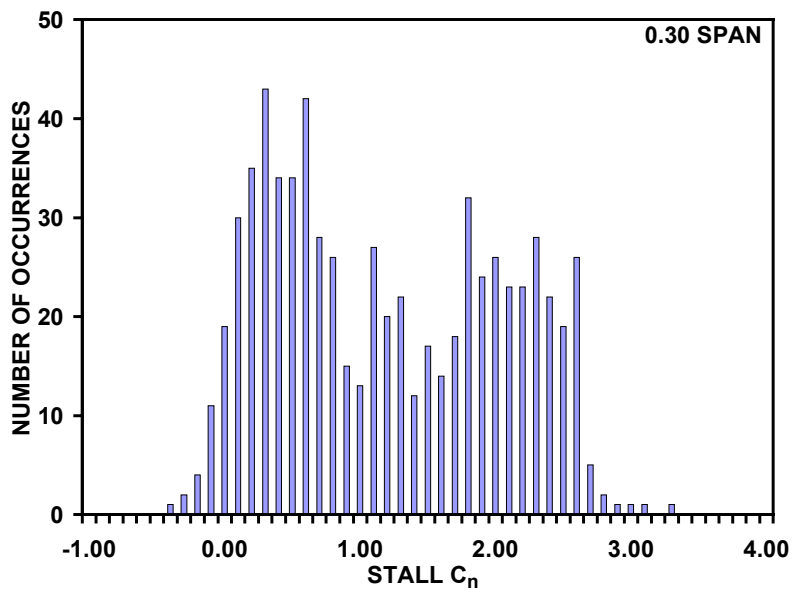

Figure 3. Stall $C_{n}$ frequency distribution at 0.30 span for campaign $\mathrm{d} 403022$.

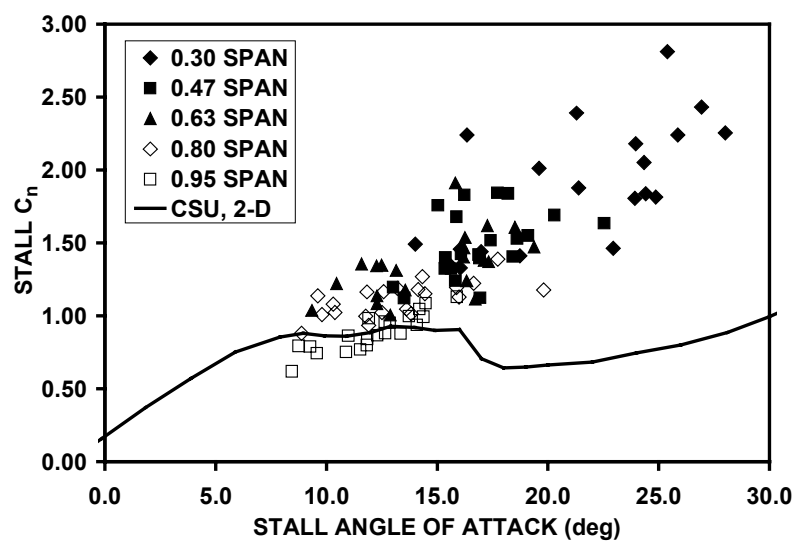

Figure 4. Stall $C_{n}$ vs. stall $\alpha$ for 21 selected cycles.

During operation at nonzero yaw, wind turbine blades experience significant $\alpha$ variation in response to blade rotation. Even in the presence of stochastic inflow and tower wake contributions, these $\alpha$ variations retain a distinctly repeatable oscillatory character. These cyclic variations can be compactly, although approximately, represented using the sinusoidal waveform parameters $\alpha_{\omega}$ (oscillation amplitude) and $\alpha_{m}$ (mean angle of attack). Accordingly, $\alpha_{\omega}$ and $\alpha_{\mathrm{m}}$ were defined as follows:

$$
\begin{aligned}
& \alpha_{\mathrm{m}}=\left(\alpha_{\max }+\alpha_{\min }\right) / 2 \\
& \alpha_{\omega}=\left(\alpha_{\max }-\alpha_{\min }\right) / 2
\end{aligned}
$$

where: $\quad \alpha_{\min }=$ minimum $\alpha$ during cycle

$$
\alpha_{\max }=\text { maximum } \alpha \text { during cycle }
$$

These two parameters were computed for all 21 cycles at all five span stations. The results are plotted in Figure 5. Also plotted in Figure 5 are two points $\left(\left(\alpha_{\mathrm{m}}\right.\right.$, $\left.\alpha_{\omega}\right)=(14.0,10.0)$ and $\left.\left(\alpha_{\mathrm{m}}, \alpha_{\omega}\right)=(20.0,10.0)\right)$ indicating pure sinusoidal $\alpha$ oscillations of a twodimensional S809 airfoil in the Ohio State University wind tunnel [26]. Finally, the line marked "STATIC STALL THRESHOLD" corresponds to combinations of $\alpha_{\mathrm{m}}$ and $\alpha_{\omega}$ that drive $\alpha$ up to the S809 twodimensional static stall threshold of $15.2^{\circ}$ just once during the cycle, but do not exceed it. Points below this line indicate $\alpha$ histories that never exceed the static stall threshold. Alternatively, points above this line correspond to $\alpha$ histories that exceed the static stall threshold, passing through the threshold twice per cycle.

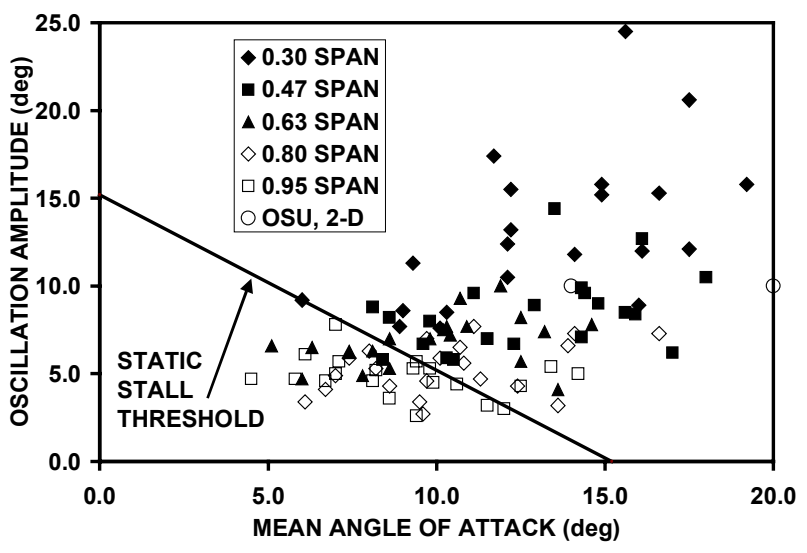

Figure 5. Oscillation amplitude vs. mean angle of attack for 21 selected cycles.

Figure 5 indicates that 0.30 span reaches the highest angles of attack and exceeds the static stall threshold for all 21 cycles. Angle of attack at 0.47 span also attains high $\alpha$, and all but one cycle exceeds the static stall threshold. Span locations 0.63 and 0.80 display similar trends, in that both experience moderately 
elevated $\alpha$, and approximately one third of cycles at these span locations do not exceed the static stall threshold. Finally, the 0.95 span location is distinct from the other four since $\alpha$ exceeds the static stall threshold in only three cycles at this span.

The trends shown in Figures 4 and 5 are consistent, attesting to the presence and influence of dynamic stall on the turbine blades. Penetrating the static stall threshold elicited dynamic stall and generated a dynamic stall vortex responsible for amplifying $C_{n}$ $[1,2]$. Generally, dynamic amplification of $\mathrm{C}_{\mathrm{n}}$ and stall delay (Figure 4) correlated well with combinations of $\alpha_{m}$ and $\alpha_{\omega}$ that penetrated the static stall threshold (Figure 5). However, some points in Figure 5 below the static stall threshold corresponded to points in Figure 4 that showed dynamic amplification and stall delay. This can be attributed to the instantaneous angle of attack increments due to induced angle of attack effects arising from blade leading edge velocity $[27,28]$.

In addition to $\alpha$ variations driven by blade rotation at nonzero yaw, equally prominent $\alpha$ fluctuations can be prompted by blade passage through the tower wake. Passage of the blade through the tower wake resembles a rapid ramp pitch up, and elicits a bifurcated response [29] likely to be distinct from the physics reported herein. The 21 cycles used in this study were chosen such that tower wake impingement on the blade did not impact the aerodynamics of interest. This is documented in Figure 6, where blade interaction with the tower wake was restricted to the gray cross hatched area marked "TOWER WAKE". The individual points represent stall $\mathrm{C}_{\mathrm{n}}$ for the five blade span locations in each of the 21 cycles. Importantly, for the 21 cycles employed herein, the events of interest either preceded blade passage through the tower wake, or followed it by a delay sufficient to allow tower wake impingement effects to dissipate prior to the onset of the events of interest.

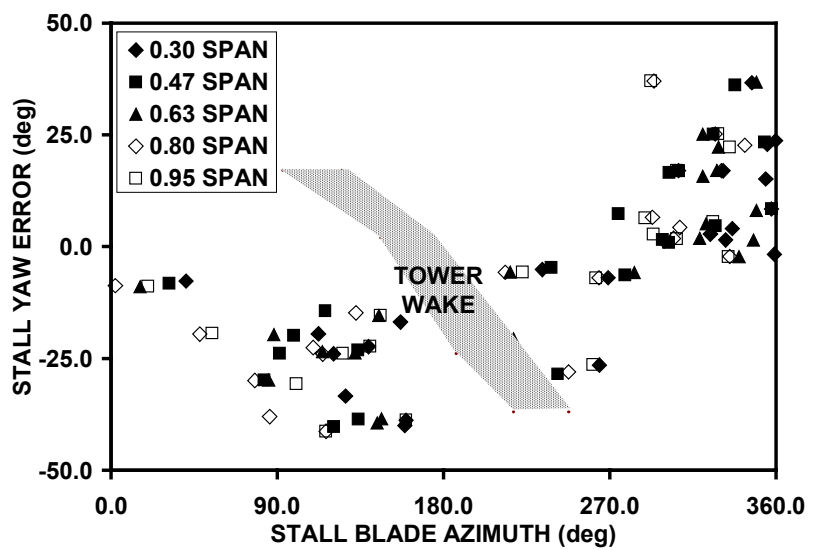

Figure 6. Stall yaw error vs. stall blade azimuth for 21 selected cycles. $\underline{\alpha, C_{\underline{n}}}$, and $\mathrm{c}_{\mathrm{p}}$ Time Series

In addition to stall $\alpha$ and stall $\mathrm{C}_{\mathrm{n}}$, time series data for $\alpha$, $\mathrm{C}_{\mathrm{n}}$, and blade suction surface $\mathrm{c}_{\mathrm{p}}$ distributions also were examined to clarify the physics of the vortex dominated flow field. Blade $c_{p}$ distributions enabled unambiguous detection and tracking of the dynamic stall vortex, as well as correlation of $\alpha$ and $C_{n}$ with dynamic stall vortex kinematics.

Blade $c_{p}$ histories are presented in Figures 7 through 10, accompanied by $\alpha$ and $\mathrm{C}_{\mathrm{n}}$ histories. The data in these four figures correspond to spans $0.30,0.47,0.63$, and 0.80 for cycle number 320 , and are representative of the $\alpha, C_{n}$, and $c_{p}$ histories for the other 20 cycles used in this study. During cycle 320, average hub height wind speed was $11.7 \mathrm{~m} / \mathrm{s}$, and average yaw error was $24.2^{\circ}$. The format is identical for all four figures, with each figure containing two panels. The upper panel shows 13 suction surface $c_{p}$ histories versus instrumented blade azimuth angle $(\psi) . \psi=0^{\circ}$ denotes the 12 o'clock position, and the blade rotates clockwise as viewed from downwind. Trace 1 corresponds to the leading edge pressure tap, with successive numbers corresponding to tap locations progressively farther aft on the suction surface blade chord. Surface pressure minima corresponding to dynamic stall vortex presence $[12,30]$ have been highlighted with an open circle symbol. The 13 traces have been offset to facilitate viewing, and zero references have been omitted. The lower panel contains $\alpha$ and $\mathrm{C}_{\mathrm{n}}$ histories, again versus blade azimuth angle. Note that $\mathrm{C}_{\mathrm{n}}$ magnitudes have been multiplied by 10 to allow plotting on the same scale with $\alpha$.

In Figure 7 ( 0.30 span $), \alpha$ reaches a minimum of $-0.7^{\circ}$ at $\psi=163^{\circ}$, excluding tower wake effects. Thereafter, $\alpha$ rises with only minor monotonicity disruptions, to a maximum of $39.9^{\circ}$ at $\psi=337^{\circ}$. In response to increasing $\alpha, c_{p}$ decreases at all 13 taps, although the rate of decrease is noticeably faster at tap locations nearer the leading edge. Decreasing surface pressures culminate in well defined $c_{p}$ minima corresponding to dynamic stall vortex presence and marked by open circles. After $\mathrm{c}_{\mathrm{p}}$ minima are attained, surface pressures again increase, signaling departure of the dynamic stall vortex. These $c_{p}$ minima occur at later times for taps farther aft on the blade chord, consistent with a dynamic stall vortex that initiates near the leading edge, and then convects aft toward the trailing edge.

At taps 1 through 8 , between $\psi=271^{\circ}$ and $\psi=285^{\circ}, c_{p}$ variation yields troughs that are deep and narrow, indicating passage of a condensed vortex structure. Between taps 8 and 9 , at $\psi=285^{\circ}$, these deep, narrow 
$\mathrm{c}_{\mathrm{p}}$ troughs are abruptly supplanted by broad, shallow $\mathrm{c}_{\mathrm{p}}$ depressions, indicating sudden alteration to the vortex structure. Subsequently, taps 9 through 13, between $\psi$ $=331^{\circ}$ and $\psi=347^{\circ}$, record similar broad, shallow depressions, indicating passage of a more expansive vortex structure. Note that the tower wake incursion, as indicated by $\alpha$, is restricted to $106^{\circ} \leq \psi \leq 137^{\circ}$, allowing ample delay for the blade flow to reestablish and wake structures to convect downstream prior to the start of the events described above.

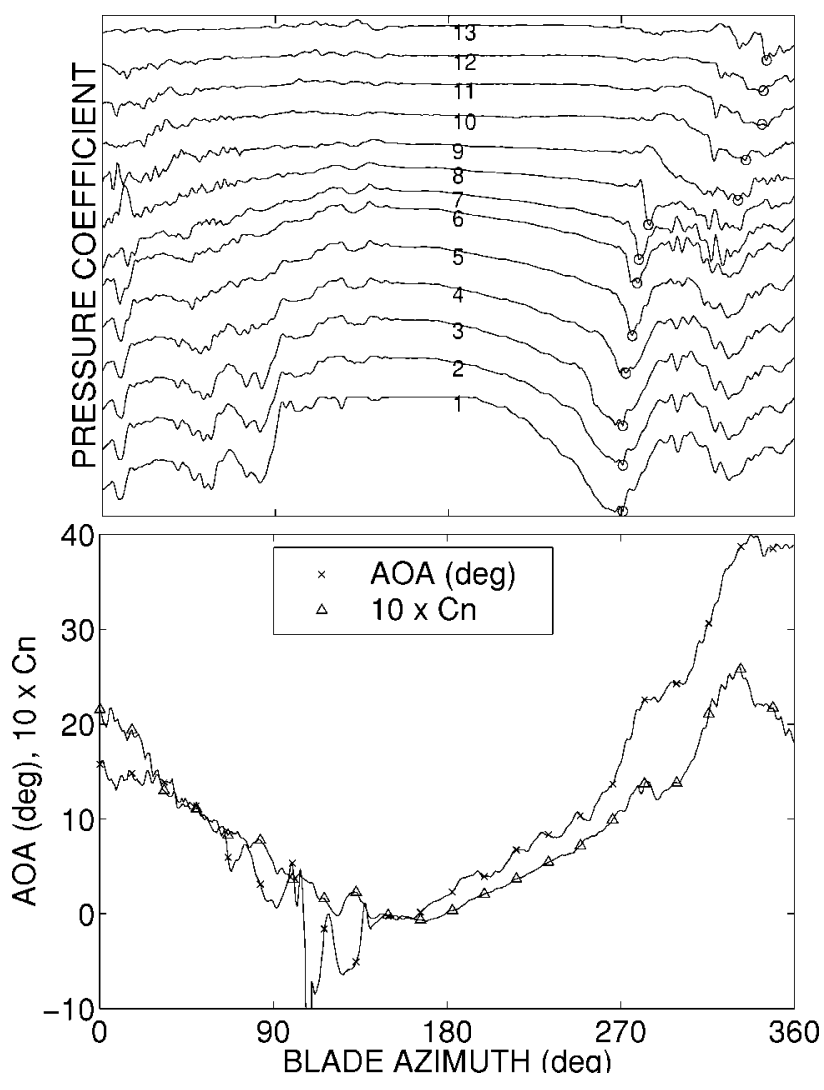

Figure 7. Suction surface $c_{p}$ histories (upper panel); angle of attack and $10 \times \mathrm{C}_{\mathrm{n}}$ histories (lower panel). Both for cycle number 320 at 0.30 span.

In Figure $7, \mathrm{C}_{\mathrm{n}}$ underwent fluctuations consistent with the $c_{p}$ variations described above. As $c_{p}$ initially decreased uniformly over the suction surface, $C_{n}$ initially increased without interruption. $C_{n}$ reached a local maximum of 1.35 at $\psi=283^{\circ}$, and then briefly decreased. At the same time the deep, narrow $c_{p}$ troughs were supplanted by broad, shallow $c_{p}$ depressions. Shortly thereafter, $C_{n}$ underwent a resurgence, rising higher, and subsequently stalling at $\psi$ $=331^{\circ}$ at a value of 2.58 , as the vortex approached the blade trailing edge.
Some surface pressure responses apparent in Figure 8 (0.47 span) are quite similar to those in Figure $7(0.30$ span). At $\psi=169^{\circ}, \alpha$ begins to increase from a minimum of $4.2^{\circ}$. This $\alpha$ increase with time proceeds unabated to a maximum of $27.3^{\circ}$ at $\psi=355^{\circ}$. In response, $c_{p}$ decreases at all 13 taps, with the rate of decrease being appreciably faster for tap locations in the leading edge region. Decreasing surface pressures culminate in unambiguous $\mathrm{c}_{\mathrm{p}}$ minima (marked by open circles), followed shortly thereafter by pressure rises, signaling the approach, presence, and departure of the dynamic stall vortex. Surface pressure minima occur at later times for taps farther back on the chord, indicating vortex initiation near the leading edge followed by convection downstream.

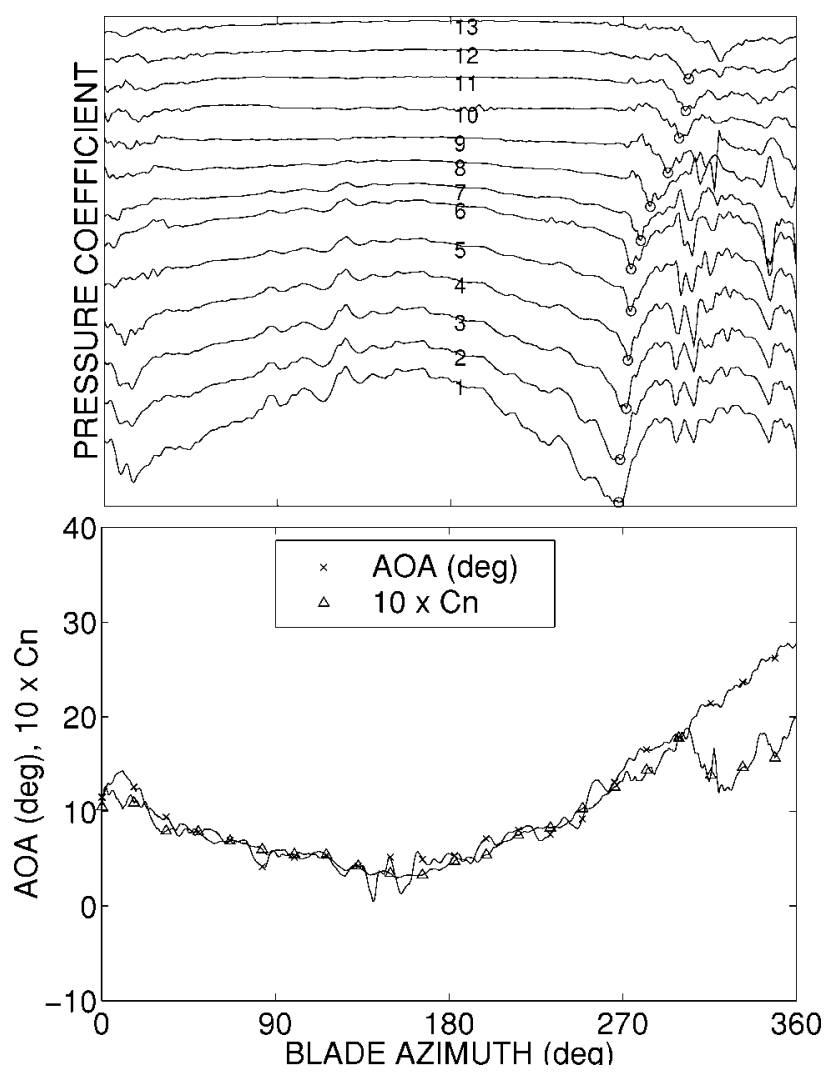

Figure 8. Suction surface $c_{p}$ histories (upper panel); angle of attack and $10 \times C_{n}$ histories (lower panel). Both for cycle number 320 at 0.47 span.

However, some behaviors in Figure 8 (0.47 span) are significantly different from those in Figure $7(0.30$ span). In contrast to Figure 7, Figure 8 shows no abrupt transition from a deep, narrow pressure trough to a broad shallow one. Instead, the Figure 8 pressure troughs are initially narrow and deep near the leading edge, and gradually broaden and become shallower as the trailing edge is approached. These $c_{p}$ fluctuations are indicative of progressive vortex growth with no 
major modification to overall vortex structure. As at 0.30 span the tower wake crossing, as indicated by $\alpha$, occurs well in advance of the event sequence of interest, and imparts negligible disruption.

As at 0.30 span, the 0.47 span $C_{n}$ variations were consistent with the $c_{p}$ fluctuations. When $c_{p}$ initially declined over the suction surface, $C_{n}$ increased without significant interruption. However, unlike $0.30 \mathrm{span}, \mathrm{C}_{\mathrm{n}}$ at 0.47 span attained no local maximum. Instead, $C_{n}$ increased without interruption, until stalling at a value of 1.84 at $\psi=302^{\circ}$ as the dynamic stall vortex reached the trailing edge.

Figure 9 (0.63 span) shows $c_{p}$ fluctuations strongly resembling those observed at $0.30 \mathrm{span}$. In response to rising $\alpha, c_{p}$ declines at all 13 taps, producing clear $c_{p}$ minima that indicate dynamic stall vortex presence (marked by open circles). These $c_{p}$ minima occur later for taps farther aft on the chord, which is consistent with a vortex initiation near the leading edge followed by convection toward the trailing edge.

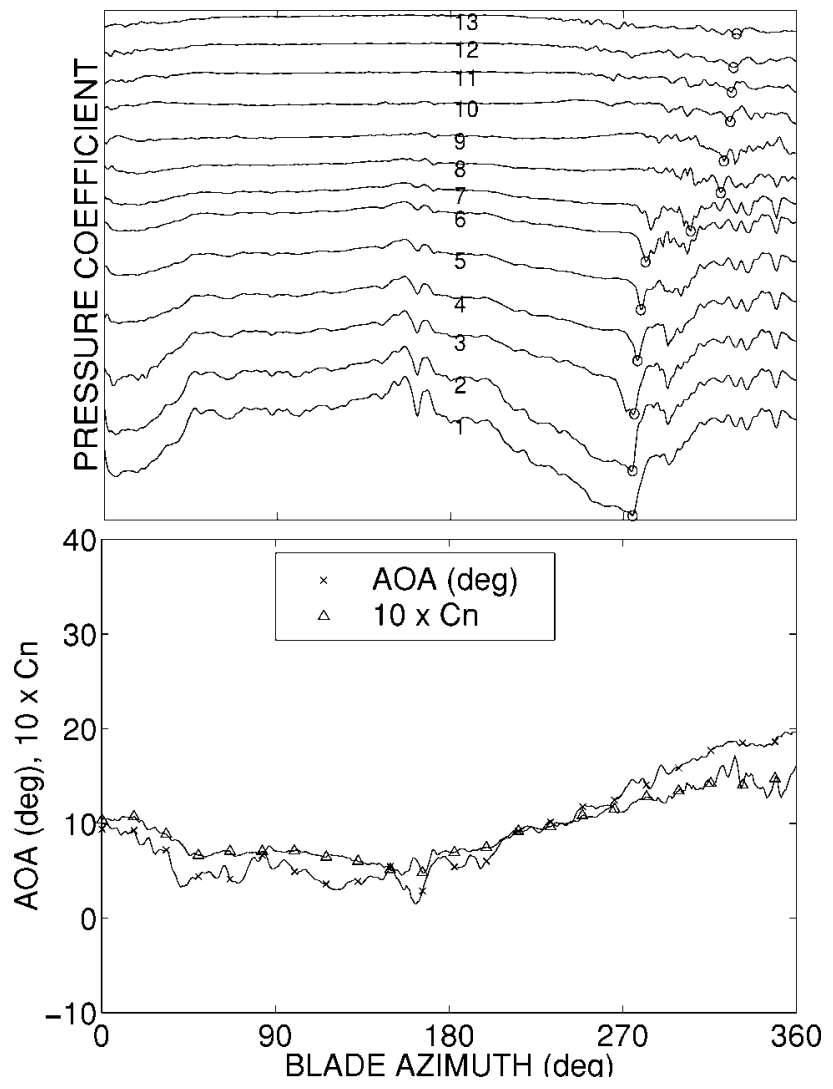

Figure 9. Suction surface $c_{p}$ histories (upper panel); angle of attack and $10 \times C_{n}$ histories (lower panel). Both for cycle number 320 at 0.63 span.
Most significant are the similarities in vortex signature development observed between 0.30 span and 0.63 span. At 0.30 span, deep, narrow $c_{p}$ troughs were observed at taps 1 through 8 , and broad, shallow $\mathrm{c}_{\mathrm{p}}$ depressions were seen at taps 9 through 13. The transition from the first type of $c_{p}$ signature to the second was abrupt, occurring over a brief time and short distance. The same is seen at 0.63 span, except that the transition occurred between taps 7 and 8 . In addition, vortex initiation, convection, and shedding followed extremely similar temporal and spatial courses. As before, $\mathrm{C}_{\mathrm{n}}$ variations reflected the fluctuations in $c_{p}$, with stall taking place at a $C_{n}$ magnitude of 1.70 , at $\psi=326^{\circ}$, as the vortex reached the trailing edge. However, at 0.63 span, no local $C_{n}$ maximum followed by normal force resurgence preceded $\mathrm{C}_{\mathrm{n}}$ stall. As before, blade passage through the tower wake did not interfere with the aerodynamics of interest. Virtually identical surface pressure signatures have been observed on pitching three-dimensional wings [12], and the associated vortex structures have been characterized in detail [13].

Figure 10 (0.80 span) stands in marked contrast to Figures 7 through 9. In the three previous figures, $\alpha$ substantially exceeded the $15^{\circ}$ static stall threshold, and stall $\mathrm{C}_{\mathrm{n}}$ levels underwent pronounced dynamic amplification beyond static levels. Concurrently, surface pressure signatures clearly revealed the presence of energetic dynamic stall vortices responsible for dynamic amplification. However, at 0.80 span, the stall $\alpha$ of $16.2^{\circ}$ only shallowly penetrates the static stall threshold. Likewise, the stall $\mathrm{C}_{\mathrm{n}}$ of 1.24 constitutes only weak dynamic amplification. Not surprisingly, the 0.80 span $c_{p}$ histories generally show attenuated $c_{p}$ minima, indicating that the dynamic stall vortices at this span are significantly smaller and less energetic than those farther inboard on the blade. In the data used for the current effort, stall vortex signatures usually were not evident in the surface pressure data at 0.80 span.

Surface pressure data for 0.95 span (not shown herein), are consistent with that presented previously. At 0.95 span, stall $\alpha$ is $14.0^{\circ}$ and stall $C_{n}$ is 0.91 . Since the static stall threshold has not been exceeded, the $c_{p}$ histories contain no evidence of a vortex structure, and stall normal forces exhibit no amplification. Data employed in the current effort showed no evidence of dynamic stall vortex presence at 0.95 span. 


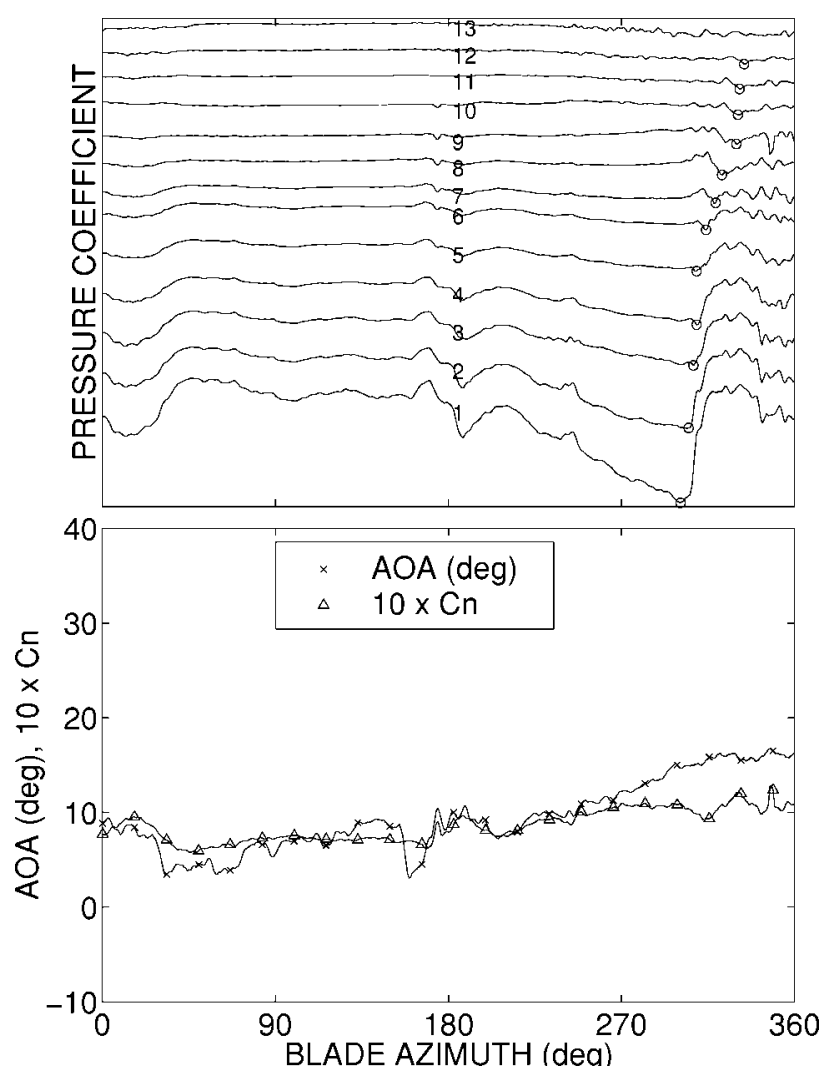

Figure 10. Suction surface $c_{p}$ histories (upper panel); angle of attack and $10 \times C_{n}$ histories (lower panel). Both for cycle number 320 at 0.80 span.

\section{$\underline{\text { Dynamic Stall Vortex Kinematics }}$}

When present, the dynamic stall vortex dominated the flow field over the blade, prompting significant stall delay and amplifying normal forces beyond static levels. To better comprehend the physics of the vortex and the influences it exercised on the blade aerodynamics, the kinematics of the dynamic stall vortex were documented in detail.

Dynamic stall vortex convection histories were extracted from $c_{p}$ histories like those shown in Figures 7 through 10, and consolidated into plots similar to that shown in Figure 11. Figure 11 documents dynamic stall vortex chordwise position versus time, where $t=0$ corresponds to $\psi=0^{\circ}$ (instrumented blade at 12 o'clock position). The data shown in Figure 11 were extracted from cycle 320, the same cycle documented in Figures 7 through 10. Typically, the dynamic stall vortex initiated at approximately the same time at $0.30,0.47$, and 0.63 span. As shown by the slopes of the plots, vortex convection proceeded at approximately the same velocity $\left(\mathrm{V}_{\mathrm{DSV}}\right.$ ) over the forward $0.10 \mathrm{c}$. Subsequently, convection velocity at 0.30 span and 0.63 span slowed appreciably between $0.66 \mathrm{~s}$ and $0.75 \mathrm{~s}$, and then accelerated dramatically. During this time, convection velocity at 0.47 span exhibited only minor variations.

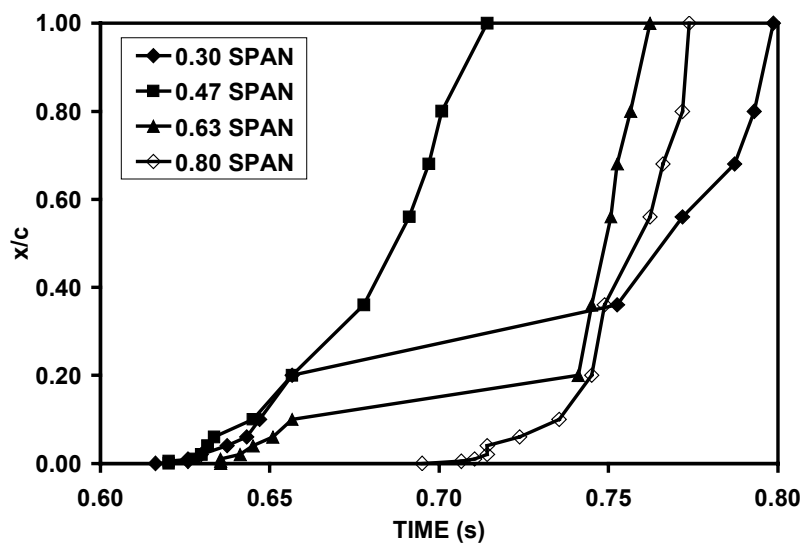

Figure 11. Representative dynamic stall vortex convection histories for cycle number 320 .

At 0.80 span, vortex initiation was delayed approximately $0.06 \mathrm{~s}$, relative to the three inboard span stations. At this span, the vortex underwent nearly uniform acceleration between $0.0 \mathrm{c}$ and $0.20 \mathrm{c}$, and then stabilized at approximately constant velocity. It should be noted that cycle 320 is atypical in that most cycles did not exhibit a dynamic stall vortex at 0.80 span.

To allow consistent comparison of vortex convection velocities across different cycles and span locations, linear least squares fits were applied to convection histories like those shown in Figure 11. This yielded average vortex convection velocity $\left(\mathrm{V}_{\mathrm{DSV}}\right)$ during vortex presence on the blade surface. In addition, reduced frequency $\left(\mathrm{K}=\mathrm{c} \omega / 2 \mathrm{U}_{\mathrm{LOC}}\right)$ was computed at each span location for all cycles. These two parameters, with $\mathrm{V}_{\mathrm{DSV}}$ nondimensionalized by $\mathrm{U}_{\mathrm{LOC}}$, are co-plotted in Figure 12. Shown on the same plot are $\mathrm{V}_{\mathrm{DSV}} / \mathrm{U}_{\mathrm{LOC}}$ corresponding to sinusoidal pitch oscillations of a two-dimensional S809 airfoil in the Ohio State University (OSU) wind tunnel [26].

In Figure 12, the points corresponding to the three span locations can be assembled into the three groups bounded by dashed boxes. Reduced frequency decreases monotonically for span stations farther outboard due to monotonically increasing local velocity. However, $\mathrm{V}_{\mathrm{DSV}} / \mathrm{U}_{\mathrm{LOC}}$ varies nonmonotically with span location. At 0.30 span and 0.63 span, $\mathrm{V}_{\mathrm{DSV}} / \mathrm{U}_{\mathrm{LOC}}$ assumes magnitudes between 0.03 and 0.17 . However, at 0.47 span, $\mathrm{V}_{\mathrm{DSV}} / \mathrm{U}_{\mathrm{LOC}}$ reaches significantly higher values, between 0.17 and 0.30 . Consistent with previous reports [31], $\mathrm{V}_{\mathrm{DSV}} / \mathrm{U}_{\mathrm{LOC}}$ for the twodimensional OSU data increases monotonically with $\mathrm{K}$. In addition, the two-dimensional OSU data lie 
approximately between the two lower point groups (0.30 and 0.63 span) and the upper point group ( 0.47 span). Clearly, the blade vortex convection velocities deviate from two-dimensional data, and fail to increase monotonically with $\mathrm{K}$. These trends indicate that pronounced three-dimensional effects influence vortex development, even near the center span of the high aspect ratio blade.

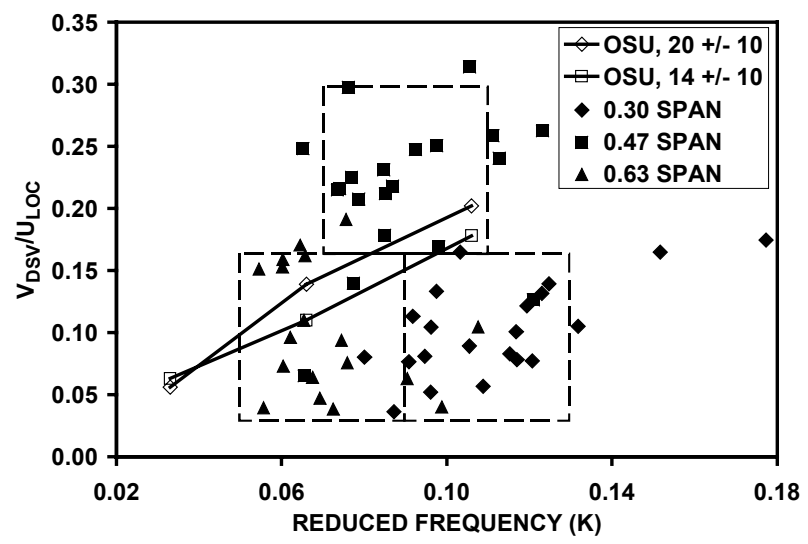

Figure 12. Nondimensional dynamic stall vortex convection velocities vs. $K$.

Vortex convection histories like Figure 11 were interpolated in time to obtain the vortex chord locations at all four span locations at equal time intervals. Using these interpolated data, vortex kinematics data from separate span locations were assembled into vortex topologies. This methodology exploits the vortex theorem of Helmholtz regarding the continuity of vorticity and vortex structures [32]. One such topology, for cycle 320, is shown in Figure 13. Here, the plot area corresponds directly to the blade planform, with the abscissa representing the blade span, and the ordinate portraying the chord. Each of the individual plots in the figure corresponds to the family of surface pressure minima at the time specified in the legend. The times in the legend are in units of seconds, with $\mathrm{t}=$ $0 \mathrm{~s}$ corresponding to $\psi=0^{\circ}$ for the instrumented blade.

Figure 13 clearly shows that the stall vortex initiates near the leading edge, and is highly two-dimensional at that time. Accelerated convection at 0.47 span couples with impeded convection at 0.30 and 0.63 span to rapidly deform the vortex, soon rendering it highly three-dimensional. Clearly, the midspan portion of the vortex reaches the trailing edge first, followed substantially later by vortex segments inboard and outboard of midspan. In contrast to the twodimensional vortex initiation between 0.30 and 0.63 span, the nascent vortex between 0.67 and 0.80 span displays substantial three-dimensionality. It first appears at a later time than the vortex inboard, and already is oriented at a considerable angle with respect to the leading edge. These temporal and spatial relationships suggest that vorticity straining may contribute to vortex coalescence at extreme outboard span locations.

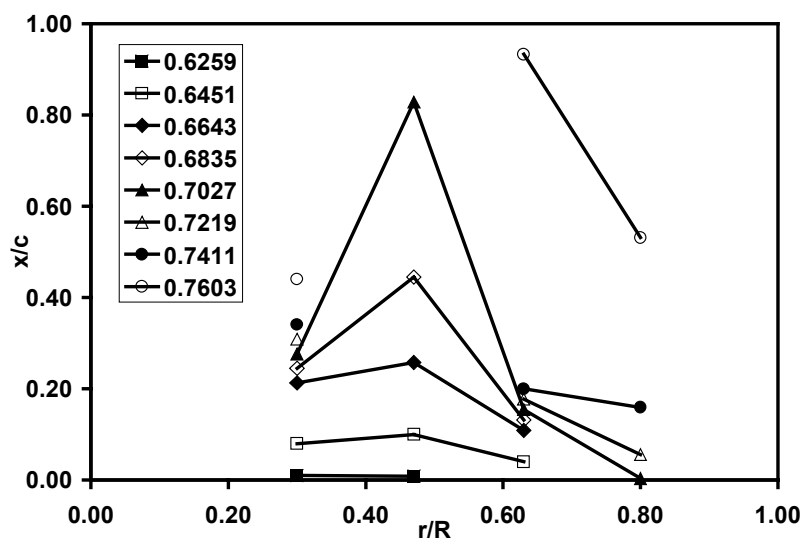

Figure 13. Representative three-dimensional dynamic stall vortex topology for cycle number 320 .

Clearly, vortex convection velocities on the turbine blade fail to vary in an orderly, monotonic fashion as a function of $\mathrm{K}$. In contrast, previous efforts using twodimensional airfoils indicate that stall vortex convection velocity varies monotonically, and even linearly, with unsteady pitching parameter.[31,33] This discrepancy suggests that other turbine blade aerodynamic influences impact dynamic stall vortex convection velocity in addition to K. Figure 14 shows the response of nondimensional vortex convection velocity $\left(\mathrm{V}_{\mathrm{DSV}} / \mathrm{U}_{\mathrm{LOC})}\right.$ to changes in $\mathrm{K},\left(\Delta\left(\mathrm{V}_{\mathrm{DSV}} / \mathrm{U}_{\mathrm{LOC}}\right) / \Delta \mathrm{K}\right)$, as a function of yaw error $(\gamma)$.

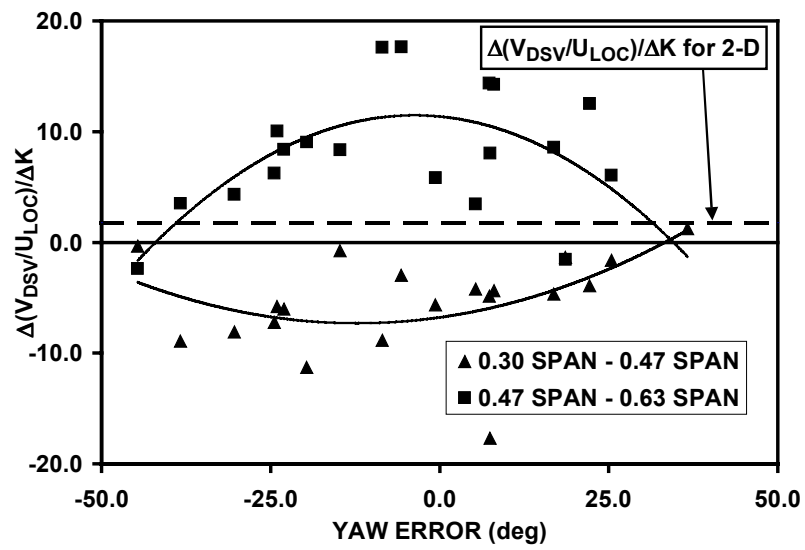

Figure 14. Vortex convection velocity sensitivity to K vs. yaw error. 
Two groups of points appear in Figure 14, one associated with $\Delta \mathrm{K}$ between 0.30 span and 0.47 span, and the other corresponding to $\Delta \mathrm{K}$ between $0.47 \mathrm{span}$ and 0.63 span. Second order least squares fits have been applied to both point groups. For 0.30 to 0.47 span, the parameter $\Delta\left(\mathrm{V}_{\mathrm{DSV}} / \mathrm{U}_{\mathrm{LOC}}\right) / \Delta \mathrm{K}$ is generally negative. This is because moving from 0.30 to 0.47 span prompts a decline in $\mathrm{K}$ and an increase in vortex convection velocity. Alternatively, for 0.47 to 0.63 span, the value of $\Delta\left(\mathrm{V}_{\mathrm{DSV}} / \mathrm{U}_{\mathrm{LOC}}\right) / \Delta \mathrm{K}$ is generally positive, since both $\mathrm{K}$ and vortex convection velocity decrease.

The horizontal dashed line in Figure 14, at $\Delta\left(\mathrm{V}_{\mathrm{DSV}} / \mathrm{U}_{\mathrm{LOC}}\right) / \Delta \mathrm{K}=1.78$, shows the sensitivity of twodimensional vortex convection velocity to changes in K. Notably, both point sets deviate considerably from this line, indicating that three-dimensionality plays a key role in these vortex dynamics. In addition, the fit trendlines reveal that turbine blade stall vortex dynamics possesses a distinct sensitivity to yaw error influences. Both point groups, representing two segments of the vortex, show the largest magnitude sensitivity to changes in $\mathrm{K}$ at yaw errors between $-5^{\circ}$ and $-10^{\circ}\left(\gamma=-5^{\circ}\right.$ to $\left.\gamma=-10^{\circ}\right)$. Both lower and higher yaw error angles produce attenuated sensitivity magnitudes, approaching zero at $\gamma=-43^{\circ}$ and $\gamma=+34^{\circ}$. These trends with respect to $\gamma$ indicate that low yaw errors elicit the most pronounced vortex threedimensionality, while larger yaw errors result in more two-dimensional vortex structures. That the data points deviate substantially from the fit trendline indicates that still other influences in addition to reduced frequency $(\mathrm{K})$ and yaw error angle $(\gamma)$ impact the kinematics of the stall vortex.

\section{$\underline{\text { Turbine Blade Vortex Structure and Dynamics }}$}

Practical considerations discourage attempts to directly visualize the dynamic stall vortex structure on the turbine blade. However, detailed surface pressure data, analogous to that documented herein for the turbine blade, exist for a three-dimensional wing pitching in a wind tunnel. [13] Furthermore, the vortical flow field over the pitching wing has been thoroughly visualized and the fluid dynamics are well understood. Comparative analyses enable knowledge regarding wing vortex structure and dynamics to be extrapolated to the wind turbine blade.

Obviously, inflow profiles and angle of attack histories in the laboratory wind tunnel differ markedly from those in the wind turbine field test environment. In the wind turbine environment alone, inflow and angle of attack display a bewildering spectrum of permutations.
However, all turbine blade surface pressure data examined in the current investigation possessed highly stereotyped features indicative of dynamic stall vortex presence, and evolved similarly with time. As documented above, the data campaign used in this study was typical of Phase IV data, and the cycles selected from that campaign for analysis herein were chosen to uniformly represent elevated $\mathrm{C}_{\mathrm{n}}$ conditions. Notably, these features and time courses were highly analogous to surface pressure data acquired on a wing pitching in a wind tunnel.

The turbine blade $c_{p}$ histories (Figures 7 through 10) bear a striking resemblance to the data acquired for the three-dimensional wing pitching in a wind tunnel. Like the turbine blade, pressure taps on the wing experienced distinct $c_{p}$ minima in response to dynamic stall vortex passage. Surface pressure histories at 0.47 span on the turbine blade were very similar to those near midspan on the rectangular wing. At these central span locations on both geometries, vortex passage manifests itself as deep, narrow $c_{p}$ troughs that gradually broaden and become shallower farther aft on the chord. In addition, surface pressure histories at 0.30 and 0.63 span on the turbine blade were very similar to those recorded inboard and outboard of midspan on the rectangular wing. At these locations, vortex passage elicited deep, narrow $c_{p}$ troughs near the leading edge, that were abruptly supplanted by broad, shallow $\mathrm{c}_{\mathrm{p}}$ depressions near midchord.

Wing surface pressure data also were exploited to characterize stall vortex convection velocities [34]. These data were compared with turbine blade data presented in the current work (Figure 12), and strong similarities were again evident. For both the blade and the wing, stall vortex convection velocities were highest near midspan, and decreased significantly at locations both inboard and outboard of midspan.

The flow field for the rectangular wing has been extensively visualized [13], and one panel from the sequence is shown in Figure 15. In this photograph, heavy black lines near the periphery of the photograph bound the wing planform. Instantaneous $\alpha$ is $32.9^{\circ}$, during a constant rate pitch up at $\alpha+=0.10$, that started at $\alpha=0^{\circ}$ and ended at $\alpha=60^{\circ}$. The vortex lies adjacent to the wing surface between the root and location A, and between the tip and location C. At locations $\mathrm{A}$ and $\mathrm{C}$, the vortex is sharply kinked and remains near the wing surface. Here, vorticity deformation significantly augments vortex-surface interaction and amplifies local suction magnitudes.[10,13] Finally, between locations A and $\mathrm{C}$, the vortex forms an arch over the central portion of the wing, with the apex located near B. Vortex 
convection velocity was substantially faster at $\mathrm{B}$ than it was at $\mathrm{A}$ or $\mathrm{C}$, due to increased exposure to the freestream flow. Notably, the shape and location of the vortex between $\mathrm{A}$ and $\mathrm{C}$ recapitulates the vortex topology presented in Figure 13.

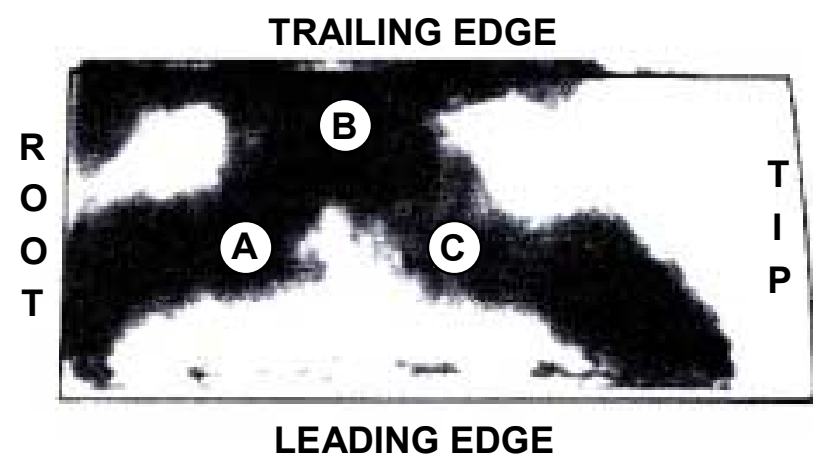

Figure 15. Visualization of three-dimensional dynamic stall vortex.

Given these strong similarities, it is likely that the turbine blade vortex qualitatively resembles the wing vortex visualized in Figure 15. Following twodimensional initiation, some portions of the blade vortex remain near the surface and, experiencing no increment to convective influence, continue to exhibit two-dimensional kinematics. At the same time, other segments of the same vortex rise above the surface and accelerate in response to enhanced freestream influence, thus producing significant three-dimensional deformation. Due to the dominant role played by the vortex, aerodynamic force generation exhibits corresponding amplification.

Although not proposed previously for wind turbine blades, the dynamic stall vortex structure hypothesized above is not singular. Similar three-dimensional vortex structures have been documented for lifting surfaces undergoing diverse pitching motions $[9,14,35,36]$. In addition, analogous vorticity concentrations have been observed on stationary wings of high aspect ratio [37].

\section{CONCLUSIONS}

Using field data acquired via the NREL Unsteady Aerodynamics Experiment, the current work provides detailed characterization of normal forces and associated stall vortex kinematics for a rotating, threedimensional turbine blade in the presence of inflow anomalies. Consistent trends and structures were evident, enabling the following conclusions to be drawn regarding the unsteady vortex mechanics of this HAWT, operating within the range of wind speeds and yaw angles stated.
Normal force amplification occurs only when the blade penetrates the static stall angle of attack threshold. This occurs frequently during routine turbine operation at all span locations except those very near the blade tip. Cyclic angle of attack variation, due to blade rotation at nonzero yaw error, is sufficient to elicit stall threshold penetration and normal force amplification. At inboard locations, stall normal forces over three times the static level are attainable, and stall normal forces twice the static level are common.

Penetrating the static stall threshold initiates a twodimensional dynamic stall vortex near the blade leading edge. This vortex rapidly convects aft, simultaneously undergoing dramatic three-dimensional deformation. Near center span, vortex convection is accelerated, while at locations both inboard and outboard of center span, vortex convection is impeded. Three-dimensional distortion of the vortex locally enhances vortex-surface interaction, and is accompanied by distinct surface pressure signatures. Normal forces, already amplified by vortex presence, are further augmented by vortex distortion.

The dynamic stall vortex generally can occupy one-half of the blade span and can be present for as much as one-fourth of the blade rotation cycle. Threedimensional blade vortex kinematics differs significantly from those observed under twodimensional conditions, responding strongly and in orderly fashion to changes in yaw error angle as well as reduced frequency. Lower yaw errors generally produce greater sensitivity to changes in reduced frequency. This, in turn, leads to more pronounced three-dimensionality at lower yaw errors.

Wind turbine vortex surface pressure signatures and kinematics are highly reminiscent of those observed for three-dimensional wings pitching in wind tunnels. Based upon this, it is likely that the midspan portion of turbine blade vortex rises above the surface and accelerates as it encounters stronger freestream convective influence. Inboard and outboard of midspan, the vortex remains near the surface and shielded from the freestream, impeding vortex convection. These pronounced disparities in convection velocity engender rapid three-dimensional deformation of the dynamic stall vortex.

This effort has disclosed dynamic stall vortex structures and interactions heretofore unrecognized as contributors to HAWT aerodynamics. These interactions are pronounced in terms of temporal extent and spatial duration. Most importantly, these interactions exercise a strong, direct impact on HAWT 
structural loads, power quality, and overall cost of energy. Extension and refinement of this work will help provide aerodynamics models of greater accuracy and robustness for wind energy machine design and analysis.

\section{ACKNOWLEDGMENTS}

The wind turbine data used in this investigation were acquired solely from the National Wind Technology Center Unsteady Aerodynamics Experiment (Phase IV). This field experiment was designed, built, and maintained by Mr. Jason Cotrell, Mr. Lee Jay Fingersh, and Mr. David Jager.

\section{BIBLIOGRAPHY}

[1] McCroskey, W. J., "Some Current Research in Unsteady Fluid Dynamics - The 1976 Freeman Scholar Lecture," Transactions of the ASME, J. of Fluids Engineering, Mar. 1977, pp. 8-39.

[2] Carr, L. W., "Progress in Analysis and Prediction of Dynamic Stall", J. of Aircraft, v. 25, n. 1, Jan. 1988, pp. 6-17.

[3] Butterfield, C., A. Hansen, D. Simms, and G. Scott, "Dynamic Stall on Wind Turbine Blades," NREL/TP257-4510, Dec. 1991. Golden, CO: National Renewable Energy Laboratory.

[4] Shipley, D., M. Miller, M. Robinson, M. Luttges, and D. Simms, "Evidence that Aerodynamic Effects, Including Dynamic Stall, Dictate HAWT Structure Loads and Power Generation in Highly Transient Time Frames," NREL/TP-441-7080, Aug. 1994. Golden, CO: National Renewable Energy Laboratory.

[5] Shipley, D., M. Miller, and M. Robinson, "Dynamic Stall Occurrence on a Horizontal Axis Wind Turbine Blade," NREL/TP-442-6912, Jul. 1995. Golden, CO: National Renewable Energy Laboratory.

[6] Robinson, M., R. Galbraith, D. Shipley, and M. Miller, "Unsteady Aerodynamics of Wind Turbines," AIAA 95-0526, $33^{\text {rd }}$ Aerospace Sciences Meeting and Exhibit, Jan 1995.

[7] Huyer, S., D. Simms, and M. Robinson, "Unsteady Aerodynamics Associated with a Horizontal Axis Wind Turbine," AIAA Journal, v. 34, n. 7, Jul. 96, pp. 14101419.

[8] Hansen, A., C. Butterfield, and X. Cui, "Yaw Loads and Motions of a Horizontal Axis Wind
Turbine," J. of Solar Energy Engineering, v. 112, Nov. 1990, pp. 310-314.

[9] Freymuth, P. "Three-Dimensional Vortex Systems of Finite Wings," J. of Aircraft, v. 25, n. 10, Oct. 1988, pp. 971-972.

[10] Robinson, M., and J. Wissler, "Unsteady Surface Pressure Measurements on a Pitching Wing,"AIAA 880328, AIAA 26th Aerospace Sciences Meeting, Jan. 1988 .

[11] Lorber, P., F. Carta, and A. Covino, "An Oscillating Three-Dimensional Wing Experiment: Compressibility, Sweep, Rate, Waveform, and Geometry Effects on Unsteady Separation and Dynamic Stall," UTRC Report R92-958325-6, Nov. 1992.

[12] Schreck, S., G. Addington, and M. Luttges, "Flow Field Structure and Development Near the Root of a Straight Wing Pitching at Constant Rate," AIAA 911793, AIAA $22^{\text {nd }}$ Fluid Dynamics, Plasma Dynamics and Lasers Conference, Jun. 1991.

[13] Schreck, S., and H. Helin, "Unsteady Vortex Dynamics and Surface Pressure Topologies on a Finite Pitching Wing," J. of Aircraft, v. 31, n. 4, Jul.-Aug. 1994, pp. 899-907.

[14] Piziali, R., "2-D and 3-D Oscillating Wing Aerodynamics for a Range of Angles of Attack Including Stall," NASA TM 4632, Sep. 1994.

[15] Himmelskamp, H, "Profiluntersuchungen an einem umlaufenden Propeller" ("Profile Investigations on a Rotating Airscrew"), Dissertation, Gottingen 1945; Mitt. Max-Planck-Institut fur Stromungsforschung Gottingen Nr. 2, 1950.

[16] Banks, W., and G. Gadd, "Delaying Effect of Rotation on Laminar Separation," AIAA J., v. 1, n. 4, Apr. 1963, pp. 941-942.

[17] McCroskey, W., and P. Yaggy, "Laminar Boundary Layers on Helicopter Rotors in Forward Flight," AIAA J., v. 6, n. 10, Oct. 1968, pp. 1919-1926.

[18] McCroskey, W. J., "Measurements of Boundary Layer Transition, Separation and Streamline Direction on Rotating Blades," NASA TN D-6321, Apr. 1971.

[19] Madsen, H., and H. Christensen, "On the Relative Importance of Rotational, Unsteady and ThreeDimensional Effects on the HAWT Rotor Aerodynamics," Wind Engineering, v. 14, n. 6, 1990, pp. 405-415. 
[20] Barnsley, M., and Wellicome, J., "Wind Tunnel Investigation of Stall Aerodynamics for a $1.0 \mathrm{~m}$ Horizontal Axis Rotor," J. of Wind Engineering and Industrial Aerodynamics, v. 39, 1992, pp. 11-21.

[21] Ronsten, G., "Static Pressure Measurements on a Rotating and a Non-Rotating $2.375 \mathrm{~m}$ Wind Turbine Blade. Comparison with 2D Calculations," J. of Wind Engineering and Industrial Aerodynamics, v. 39, 1992, pp. 105-118.

[22] Butterfield, C., W. Musial, and D. Simms, (1992). "Combined Experiment Phase I Final Report." NREL/TP-257-4655. Golden, CO: National Renewable Energy Laboratory.

[23] Miller, M., D. Shipley, T. Young, M. Robinson, M. Luttges, and D. Simms (1995), "Combined Experiment Phase II Data Characterization.” NREL/TP 442-6916, Golden, CO: National Renewable Energy Laboratory.

[24] Fingersh, L., D. Simms, C. Butterfield, and M. Jenks, "An Overview of the Unsteady Aerodynamics Experiment Phase III Data Acquisition System and Instrumentation," ASME Energy and Environment Expo '95, Houston, TX, Jan.-Feb. 1995.

[25] Acker, T., "Further Analysis of Data from the Unsteady Aerodynamics Experiment, Phase III and Phase IV," Task 2 Report, Subcontract No. XAT-818211-01, Golden, CO: National Renewable Energy Laboratory.

[26] Reuss Ramsay, R., M. Hoffman, and G. Gregorek, (1995), "Effects of Grit Roughness and Pitch Oscillations on the S809 Airfoil," NREL/TP 442-7817, Golden, CO: National Renewable Energy Laboratory.

[27] McCroskey, W., K. McAlister, L. Carr, and S. Pucci, "An Experimental Study of Dynamic Stall on Advanced Airfoil Sections," (3 Volumes), NASA TM84245, July, 1982.

[28] Strickland, J., and G. Graham, "Dynamic Stall Inception Correlation for Airfoils Undergoing Constant Pitch Rate Motions," AIAA J., v. 24, n. 4, Apr. 1986, pp. 678-680.

[29] Robinson, M., D. Simms, M. Hand, and S. Schreck, "Horizontal Axis Wind Turbine Aerodynamics: Three- Dimensional, Unsteady, and Separated Flow Influences," FEDSM99-S295-01, $3^{\text {rd }}$ ASME/JSME Joint Fluids Engineering Conference, July, 1999.
[30] Walker, J., H. Helin, and J. Strickland, "An Experimental Investigation of an Airfoil Undergoing Large Amplitude Pitching Motions," AIAA 85-0039, AIAA $23^{\text {rd }}$ Aerospace Sciences Meeting, Jan., 1985.

[31] Schreck, S., and M. Luttges, "Unsteady Separated Flow Structure: Extended K Range and Oscillations Through Zero Pitch Angle," AIAA 88-0325, AIAA $26^{\text {th }}$ Aerospace Sciences Meeting, Jan. 1988.

[32] Prandtl, L. and O. Tietjens, Fundamentals of Hydro- and Aeromechanics, Dover Publications, New York, 1957, pp. 197-200.

[33] Lorber, P., and F. Carta, "Unsteady Stall Penetration Experiments at High Reynolds Number," UTRC Report R87-956939-3, Apr. 1987.

[34] Schreck, S., and W. Faller, "Encoding of ThreeDimensional Unsteady Separated Flow Field Dynamics in Neural Network Architectures," AIAA 95-0103, AIAA $33^{\text {rd }}$ Aerospace Sciences Meeting and Exhibit, Jan. 1995.

[35] Schreck, S., "Experimental Investigation of the Mechanisms Underlying Vortex Kinematics in Unsteady Separated Flows," (Dissertation) Graduate School, University of Colorado, Boulder, CO, 1989.

[36] Horner, M., G. Addington, J. Young, and M. Luttges, "Controlled Three-Dimensionality in Unsteady Separated Flow About a Sinusoidally Oscillating Flat Plate," AIAA 90-0689, 28 $8^{\text {th }}$ Aerospace Sciences Meeting, Jan., 1990.

[37] Winkelmann, A., and J. Barlow, "Flowfield Model for a Rectangular Planform Wing beyond Stall," AIAA J., v. 18, n. 8, Aug. 1980, pp. 1006-1007. 